\title{
ENERGY LITERACY, RECYCLING AND RATIONAL USE OF MATERIALS IN THE DAILY LIFE IN STUDENTS OF THE FIFTH CLASS PRIMARY SCHOOLS OF AN URBAN AREA
}

\author{
Dimitrios Poimenidis ${ }^{1 *}$, Vasileios Papavasileiou ${ }^{2}$ \\ ${ }^{1} \mathrm{Dr}$, University of the Aegean, Greece, poimenidis@aegean.gr \\ ${ }^{2}$ Assoc. Prof. Dr., University of the Aegean, Greece, vpapavasileiou@rhodes.aegean.gr \\ ${ }^{*}$ Corresponding Author
}

\begin{abstract}
Decreasing the ecological impact, through the reduction or non-use of material and energy, is an important modern educational challenge in the context of education for sustainable development. Information, environmental awareness and enhancing students' critical thinking shape tomorrow's critically-minded adult citizens. The purpose of this research is to capture and highlight the basic knowledge, perceptions and daily practices of using material and, indirectly, energy, in the daily lives of children, counting their existing energy literacy. It was implemented in 132 students of Fifth Grade of three primary schools in an urban area of Rhodes using a questionnaire of 19 closed-ended questions. The data were analyzed with the statistical program SPSS 23 and are presented descriptively. The results of the study show that the bicycle was chosen by a limited number of children, as an environmentally friendly mean of transportation. However, yet, many children travel on foot to and from school, contributing significantly to saving resources. Also, according to their statements, they save a lot of water in their various daily personal uses, such as brushing their teeth, their faces, using a shower for their physical hygiene and washing their family car. Nevertheless, they use an extensive amount of bottled water as drinking water, resulting the deterioration of the issue plastic production and management. Although they know a lot about the issue of transporting food from distant areas, they still consume a lot of such foods in their daily life, while vegetarianism is extremely rare as a way of eating, as well as their knowledge about local seasonal fruits. They, also, state that there is a very significant degree of recycling and separation of materials in the school units they attend, while in their homes it is implemented to a lesser degree compared to schools. Furthermore, while the recycling of light bulbs is generally carried out to a significant degree, their placement to special lamp bins instead of light glass bins in ordinary glass bins is sometimes confused. This is also the case for batteries. When it comes to printing files on a printer, there is generally good paper handling and reuse, but not enough ink savings. Also, from their statements, it appears that packaging materials are taken into account to a significant extent when purchasing products. Overall, there is quite environmentally friendly behaviour which, of course, needs to be reinforced with specialized teaching approaches in the context of education for sustainable development and a possible final repetition of the study at a later time for the evaluation of interventions in the context of energy literacy.
\end{abstract}

Keywords: Energy literacy, material management, embedded energy, knowledge, views

\section{INTRODUCTION}

Energy is a driving force of modern social and economic life, as it is considered absolutely necessary in all human functions (Owusu \& Asumadu-Sarkodie, 2016; DeWaters \& Powers, 2008). Furthermore, it is one of the major environmental issues of the $21^{\text {st }}$ century, as the great dependence on this generates a host of environmental issues (Stulz et al., 2011), increases pollution, a global problem affecting all of humanity, 
defined as the presence and concentration of certain types of physical, chemical, or biological agents in the environment that are harmful to human health, safety, and well-being, animals and plants (Manisalidis et al., 2020). Energy use is linked to a non-sustainable development model, which degrades the natural ecosystem and degrades the biological conditions for healthy living of all living things, through degradation of all natural elements (European Environment Agency, 2019; Vezzoli et al., 2018), when it relies mainly on conventional energy sources. Naturally, in a sense, their intensive use has created the modern economic, social and industrial conditions, which it still supports seamlessly and uninterruptedly (DeWaters \& Powers, 2008).

However, securing energy resources to maintain modern human well-being, without intensifying efforts to reduce or not use energy, also raises issues of dependence and the need to secure energy resources, even clashing with geopolitical issues between states and their societies (Hengel, 2019; Ole Gunnar, 2018; Correljé \& van der Linde, 2006). In contrast, the widespread installation of Renewable Energy Sources $(R E S)$, offers a sustainable environmental perspective and economic prosperity for each country at the same time (Maqbool et al., 2020). Along with RES, energy efficiency, decentralization of energy production and synergies between different sectors, require the implementation of new methods and energy planning policies (Dobravec et al., 2021).

Not only does man use energy in his daily life in a direct and functional way, but also indirectly, as "embedded or gray energy". This is defined as "the sum of the energy requirements associated, directly or indirectly, with the provision of a good or service" (Tuladhar \& Yin, 2021; Cleveland \& Morris, 2009) or as the energy required to construct a useful object or material, while being accompanied at the same time by the concept of embedded carbon (Hanania et al., 2018). Thus, through the production, the disposal, the transport-movement by means of transport, the use of materials (Densley Tingley \& Davison, 2011), the rejection of these, the unconscious individual practices and behaviours of man most of the time, without realizing the very extent of the impact of its choices on environmental degradation have a significant effect on the indirect use of energy. The use of materials and recycling (Ferronato \& Torretta, 2019), transportation and our choices regarding them (Henke et al., 2020), the use of foods that reduce our energy footprint (Ritchie, 2020), water management resources and reducing their misuse (Aither, 2018) are some areas of discussion, reflection and effort towards a sustainable future.

Energy today is an extremely important condition for the development and maintenance of a development model for modern societies, being essential for all human activities (Akitsu et al., 2017). Everyday life requires energy in various areas, such as transportation, heating and cooling, cooking, lighting, entertainment, etc. (Edenhofer et al., 2011). Human choices, in relation to it, also determine the effects on the environment. Man can do a lot to reduce it. People can use less energy and with more wisdom, that is, they save energy and use it to its maximum energy efficiency (United Nations, xx), or not to use it at all, where possible. Huge amounts of resources are wasted both on the production and disposal of energy, as end-use energy (functional energy), and on convertible energy from one form to another (in the sense of its degradation). The average European consumes about $27 \mathrm{MWh}$ of electricity per hour and emits huge amounts of carbon dioxide $\left(\mathrm{CO}_{2}\right)$ into the atmosphere, resulting in climate change and a simultaneous increase in global average temperature (EEA, 2019).

Improving living standards, economic prosperity and increasing the earth's population contribute significantly to the production of municipal solid waste in developing cities (Minghua et al., 2009; Guerrero et al., 2013). A well-managed and effective waste management program, however, increases the quality of health and the environment locally and more widely (Warunasinghe \& Yapa, 2016). Recycling can have significant positive effects on waste reduction and energy consumption (European Commission, 2016). The use of recycled materials in the productive industrial process results in significant energy savings (gray or embedded energy) compared to that required for the production of new materials for use from the beginning and on the processes of collection of raw materials from nature, which require complex editing (Grosse \& Mainguy, 2010). In particular, according to Environmental Protection Agency (EPA, 2016), aluminum can be recycled using less than $5 \%$ of the energy used to make the original product from raw materials. The production of plastics from recycled used plastic requires only $2 / 3$ of the energy needed for its respective primary production. Glass requires $30 \%$ more energy when not reproduced from recyclable glass. Recycling steel and other metallic materials save $60-74 \%$ of the energy consumed to produce them from raw materials. One tone of recyclable steel saves energy equivalent to 3.6 barrels of oil. In addition, the production of recycled paper requires about $60 \%$ of the energy required to produce paper from virgin pulp. Particulary, the production of one tone of recycled paper for offices and computers can save 3,000 to 4,000 Kwh compared to the production of raw materials. Given the benefits of recycling, society needs to adopt this practice as normal daily behaviour (Aguilar-Jurado et al., 2019). However, at European level there are differences in municipal waste management, as a large part of these is not used as a resource (Scarlat et al., 2018), while 
solid waste management is one of the most important challenges (Abdel-Shafy, \& Mansour, 2018).

Transport, which is an important sector of modern life, consumes huge amounts of hydrocarbons-derivatives of crude oil and natural gas. Globally, oil and other liquid fuels dominate as a source of energy in transport (Energy Information Administration, 2016). According to the World Petroleum Council (WPC, 2020), about $80 \%$ of global demand fuel transport (road, rail, air and sea) is currently covered by fossil fuel derivatives. Due to these, significant amounts of greenhouse gases are released, which worsen the natural environment, while natural resources are wasted (D'Agosto, 2019). The carbon footprint in the ecosystem is strengthened, due to individual and collective pressure. Therefore, at the level of individual responsibility, especially in transport, where possible, we should travel on foot or by bicycle (Brusarosco, 2015; Khalil, 2018).

A similar issue is the transport of products from region to region (kilometres of food), which are also associated with a number of environmental issues (Weber \& Matthews, 2008). This is also the case for household housing (Tukker \& Jansen, 2006). Foods and items that are produced in a specific area are transported for consumption, at a rate of $17 \mathrm{~kg}$ per $100 \mathrm{~kg}$ of production, over quite long distances (Poore \& Nemecek, 2018). This process is energy-consuming. Local production, distribution of products and the use of foodstuffs from the immediate human environment would partially reduce energy waste. Moreover, the choice of local food has a reducing effect on greenhouse gas emissions and energy consumption. For example, the consumption of products of animal origin worsens their production cycle, as for every kilo of beef, $60 \mathrm{~kg}$ of carbon dioxide are emitted in relation to one kilo of peas, for which only $1 \mathrm{~kg}$ is emitted. Emissions from poultry and pork are quite limited but are still higher $\left(6-7 \mathrm{~kg}\right.$ of $\mathrm{CO}_{2}$ equivalents) than most plant foods (Ritchie, 2020). Consumption of food of animal origin, coming from a distant region to a region that lags in livestock, maximizes energy consumption and greenhouse gas emissions.

The provision of drinking water is also an important issue, as its existence is extremely limited, while there is a serious issue of its disposal, access, use and recycling (Ritchie, 2019). Its waste, the production of large amounts of wastewater, irrigation, recycling, etc., are a set of processes, which are also related to energy waste (Kavvada et al., 2016). Its rational management, reduction of urban wastewater and its reuse contribute to water, energy and money savings and at the same time offer significant environmental benefits to primary sources and drinking water storage facilities (Sustainable Water, 2018).

The sectors included in the present analysis, concern energy waste of operating energy about $30 \%$ of the total daily need of the citizens, while their integrated or gray energy waste can reach $70 \%$. This is argued because the energy waste of integrated energy includes areas related to trade products, transport, products from processing, food, beverages and agricultural products (Supasa et al., 2017). People's preferences regarding their food choices, energy use in their homes, and transportation and transportation significantly determine consumerism and the environmental impact of their choices (Scarlat et al., 2019).

\subsection{Student Education}

The areas mentioned are directly related to the daily choices of the student environment. They are a field in which school education can clarify issues, shape perceptions, enhance practices, provide information and ultimately educate students who are environmentally aware and informed about the direction of sustainable development (Papavasileiou, 2015). For these reasons, school education requires the implementation of environmental programs in the context of sustainability education, which provide sufficient information, clear guidance, multiple implementation methods and specific objectives, framed by a wider range of environmental, social, political and economic issues, which are related to each other. A sustainable school that tries in various ways to meet modern learning requirements, pursuing the principles and methodological requirements of Environmental Education and Sustainable Education (Papavasileiou et al., 2018).

Today, environmental protection is an issue of paramount importance with ecological, political, economic and social dimensions. The school is an institution that utilizes a wealth of information and knowledge to raise awareness of current environmental problems, develop ecological awareness and take active action. The sustainable school tries in every case to meet the modern learning requirements, seeking to make a decisive contribution to the achievement of the goals of sustainability (Papavasileiou et al., 2017). In fact, given that In Greek reality there is a great geographical fragmentation, it affects all those aspects of matter and energy management. Thus, all those local elements that shape and influence the level and context of students regarding energy should be taken into account, in order to make the current public school sustainable (Papavasileiou, 2015). After all, a very important goal of the educational process is to form a conscious, critical-minded and environmentally aware citizen of tomorrow, who is called to shape his future background today as an adult, who will make decisions about his future and change his behaviour aiming at the longterm concept of wider energy literacy and not just its temporary adaptation (Cotton et al., 2015). 


\section{METHODOLOGY}

The study examines the key aspects of the daily management of materials and energy and behaviour in the personal lives of three primary school students based on their energy literacy. Implemented in 132 children, students of the Fifth Grade class of three municipal urban area schools, after the completion of the cycle of courses in the chapter "Energy" of the subject of Physics. It is a second study, part of a broader research approach focusing on the aspects that compose the issue of energy literacy in primary school. The perceptions of children and their real daily behaviour in the issues of the present study, present the effective or ineffective management of materials and energy in their daily lives. At the same time, the degree of effectiveness of the teaching regarding their energy literacy and especially in the integrated energy emerges.

The study is quantitative with qualitative characteristics. The data were analyzed with the statistical program SPSS Statistics 23. It was implemented through a structured and anonymous questionnaire, as this is considered the most appropriate methodological tool to investigate the examined issues (Young, 2015). It includes, in total, 19 questions/statements, mainly closed-ended with individual sub-questions, which constitute a complete and integrated daily unit in children's lives. The results show the environmental "profit" or "cost" that arises from the field of energy literacy of children and their daily/routine actions and practices, mainly in areas of behaviour and management, which are secondary to gray or embedded energy. In the fields of investigation, issues of anonymity and ethics are observed. The research is a case study.

The sample of the study comes from three different school units with proportional participation of school students on the percentages of the sample of the study $(33.3 \%, 31.8 \%$ and $34.8 \%)$ with 132 child participation. Boys comprise $56,7 \%$ whereas girls $42.4 \%$ of the $E$ grade students. The results of the study are analyzed by percentage descriptive analysis and are presented progressively in areas or topics of investigation, which relate to transport, water use, food kilometers, material recycling and waste management in the personal, mainly life of students and their families.

\section{RESULTS}

The transport sector is a very energy-intensive sector in the daily life of the average person. The way of transportation on a daily basis is a field of educational approach in the context of the energy education of the students. Ordinary means of transport were introduced to the children. Among the proposed means of transportation, hierarchically from the friendliest to the most energy-intensive, with first choice being the friendliest and lastly the least friendly depending on the carbon dioxide $\left(\mathrm{CO}_{2}\right.$ emissions), the expected answers of the students were the first choice the bicycle (100\%), a completely environmentally friendly means of transport (with the exception of walking). But (only) $30.3 \%$ of children chose the bicycle as the most environmentally friendly means, the car with its driver chose $36.4 \%$, the car with more than one passenger chose $18.2 \%$ of children and the bus the other children (15.2\%).

Many students, of course, for their daily commutes, state that they come to school on foot $(60.6 \%)$, as they live in the nearby school area, $1 / 3$ come by car $(33.3 \%)$ and a few $(6.1 \%)$ children are transported by public transport.

The sector of water use is an important part of the burden in terms of energy, but also natural resources directly and indirectly. It is also a serious local issue in an area whose reserves are not rich, while the conditions for securing it burden the local environment and the local community financially, socially and environmentally, through a network of complex processes. In addition, its excessive use and the creation of wastewater, creates the need for recycling, an issue that requires a variety of processes and energy use, burdening the local environment.

Most children (63.6\%) state that, when washing in the bath or shower, they mainly choose the short shower with simultaneous closing of the water supply, when water is not necessary. Thus, they save a great deal of clean water and energy and reduce the generation of sewage, which needs treatment or biological treatment. About $1 / 5$ of children (21.2\%) choose to take a longer shower, thus spending more water due to duration, turning off the water supply again when they do not need it. However, the rest children (15.2\%), take a longer bath, a practice which is considered the most energy consuming and harmful to the environment.

Respectively, they realize significant water savings and indirect energy savings when brushing their teeth, as $93.9 \%$ of children turn off the tap when brushing, a highly environmentally friendly practice. Only $6.1 \%$ of children waste water, ignoring its proper use. Regarding the washing of the family cars, many children $(69.7 \%)$ state that their parents wash their cars once or twice a month, a few children report washing them once a week (24.3\%), while the rest children report not having a car $(6.1 \%)$. 
Kilometers of food are a dimension of environmental degradation as, foods that are produced in areas and countries far from the local community and Greece, significantly burden the environment by intensifying the waste of energy through commercial transport. Reducing the consumption of such products results in significant energy savings and the release of pollutants into the atmosphere.

The statements of the students show that a lot of families check whether the products come from nearby areas or domestic production (87.9\%). Few families do not control this parameter $(12.1 \%)$. In practice, however, only $36.4 \%$ of families consume such foods once or twice a week, maintaining a fairly environmentally friendly behavior. Of the other households, others consume such foods on a daily basis (39.4\%) - although they stated that they take into account the kilometers of food and others quite often $(24.2 \%)$. Their statements show some inconsistency and fragmentation between the initial position and the implementation of this practice.

Frequent consumption of meat enhances the intensification of livestock production, resulting in the waste of energy and resources and the amplification of greenhouse gases with methane $\left(\mathrm{CH}_{4}\right)$, which exacerbates the greenhouse effect. It is observed, therefore, that many families of students consume meat at a relatively low frequency (1-2 times) per week $(63.6 \%)$, while several families $(33.3 \%)$ consume meat more often. Few families (3\%) do not eat meat, as they state that they are vegetarian.

Seasonal fruits are usually associated with immediate consumption as they do not need preservation and storage procedures. Only $39.4 \%$ of children report that they know about the current seasonal fruits in Greece but there are not enough reports about what they are and what they are consumed.

Waste management and recycling issues are an important component of mitigating the environmental impact of energy production and use and the waste of useful materials and natural resources, which are disposed of as waste in the environment. Naturally, the most appropriate behavior is the non-use of materials, but also minimizing the use of materials and their reuse.

The issue of disposal and use of drinking water seems to be dominated by the bottled water market $(75.8 \%)$, which creates a waste of resources and energy, both in production, disposal, and water transport to the final consumer as well as management issues of plastic packaging, worsening the ecosphere. This issue is important at the local level, as the supply of water from natural local resources is guaranteed in terms of water quality and supply and transmission network services to the final consumer by local water services. However, only $1 / 4$ of the families drink water from the water supply network (24.2\%). This is an important issue for the re-education of children.

Regarding the printing of files on computers and printers in the family life of children, it is observed that several families rarely print files (39.4\%), sometimes they print occasionally and according to their needs $(48.5 \%)$, while very frequent printing files are implemented by a small number of families $(12.1 \%)$. This results in satisfactory energy savings, reduced disposal of toxic materials into the environment (when paper is not recycled) and reduced tree felling. At the same time, in cases where files are printed (documents-texts, etc.), it is stated that available color and paper saving settings are used a lot (45.5\%), but often not (54.5\%). Printed papers, which are no longer immediately useful, are used - by their non-printed side - as drafts for texts or notes or other uses by many children (66.7\%). Some children do not though (33.3\%).

The environmental impact of the packaging of a product on the environment is taken very seriously by several children (45.5\%), sometimes by $36.4 \%$ of children, while a few children $(18.2 \%)$ state that they not take into account the issue of the packaging of the products they purchase. They do not comprehend the impact that the packaging of the product has on the entire cycle of creation, use or disposal of the packaging.

The ability to provide recycling processes is considered important to minimize the dumping of waste into the environment, both at school and at the home of three students. Therefore, there should be processes and programs for the collection and recycling of materials within the school unit. The majority of children (93.9\%) state that recycling is done in the school unit they attend, in all known categories of materials such as metal, paper, glass and batteries, while a small number of children $(6.1 \%)$ seem not to understand the procedures. recycling within the school. In their homes, as they state, the recycling processes are implemented by many families (54.5\%). However, $45,5 \%$ of the families (45.5\%) (a high percentage for the data of modern reality), do not recycle materials that can be recycled (bottles, aluminum cans, batteries, etc.), even those that are particularly harmful to nature (batteries), which end up, along with the rest of the waste in landfills, significantly burdening the environment.

Recyclable material is also energy saving lamps, which should be placed in special bins and not in those for ordinary glass. Several children (39.4\%) state that their families place non-functional light bulbs in a special 
light bulb recycling bin, while the rest of the children report either placing light bulbs in standard glass waste bins $(42.4 \%)$, a significant issue. improper environmental behavior, or, in the worst case, in common waste bins $(18.2 \%)$. Therefore, this issue is also an important field for information through targeted educational interventions.

\section{DISCUSSION AND CONCLUSIONS}

The daily practices and behaviors of children in the the personal and family life regarding the use of materials, the implementation of practices and the adoption of behaviors, demonstrate the degree of achievement of energy literacy in the field of gray or embedded energy. They show the level of knowledge, information, perceptions and behavior on the issue of gray or embedded energy, which is not immediately perceived by students, as well as the average citizen. Another issue is that the type of this energy (embedded or gray energy) is not sufficiently clarified in the educational process, but appears as a parameter among the other dimensions related to issues such as waste, material management, etc. Education, however, should familiarize students with rational energy management and the learning and application of energy-saving practices in their daily lives through a variety of teaching approaches (Lefkeli et al., 2018). Undoubtedly, it is worth noting, that quite often school curricula and didactic approaches to energy literacy focus on direct or functional energy, the results of which are immediately apparent, controllable and achievable more consciously. The results of the present study highlight the areas in which there is a lack of knowledge, and limited adoption of environmentally friendly behaviors and practices by students. These elements need targeted retraining to enhance students' cognitive background and strengthen energy saving best practices, which are absolutely necessary in the context of sustainability (Ntona et al., 2015). Furthermore, clarifying the context of this deficit, what is not being achieved or what can still be improved, can make a positive contribution to making appropriate policy and educational choices in the context of specialized teaching approaches and interventions, harmonized with indirect and otherwise difficult to understand of the issue of gray energy. In general, the energy secretariat of primary school children is based not only on the production and consumption of electricity, the social and environmental effects of its production, distribution and use, but also on the behaviors and correct decisions in this matter (Martins et al., 2020).

The results of the study on the transport sector show a limited use of the bicycle, a means that is completely friendly and familiar to most children and environmentally friendly in relation to the emissions of air pollutants. Perhaps, it is justified by the lack of bike lanes. Naturally, the movement is done mainly on foot in most cases and especially in the movement to the school unit and this practice is very important and environmentally friendly.

Regarding water management, as shown by the statements of the students, it seems that both the children themselves and their parents make careful use of the water in the washing of the family vehicles, when brushing their teeth and the duration of their physical hygiene, by interrupting the flow of water and using small and short showers. These practices significantly reduce the loss of valuable water and indirectly the use of gray energy.

However, as far as the origin of the products for their purchases is concerned, it seems that, only a limited number of families often buy essential items produced from their immediate environment, while most buy products from other remote areas. This exacerbates the increase in food kilometers and weakens local production of items, as only a part of the economic cycle is implemented in the local community and in particular in primary production. A similar issue is meat eating, as there is quite frequent consumption of meat, even imported from other regions, since local production is extremely limited, while vegetarianism, as the main diet, is a parameter that limits water consumption, the increase of methane in the atmosphere and is almost zero.

In relation to the recycling of materials, it is observed that a large number of individuals and families buy bottled water, although it is not necessary due to the safe local water supply system and the quality of the water provided. This issue contributes to the increasing use of plastic bottles and the need to collect and recycle them, while this whole process could be extremely limited.

Regarding the issue of file printing and paper use, as it appears from the statements, there is generally rational behavior and use of paper materials and inks, but also reuse of already used paper secondarily, a practice that significantly contributes to reducing the environmental impact. The impact of the packaging of the products on their purchase is still sufficiently taken into account, but when it comes to disposing of light bulbs that are made, it seems to be confusing to dispose of them in special collection bins and sometimes placed in common bins for glass or other waste bins. 
Finally, on the issue of the possibility of recycling materials as a whole practice and way of life, it seems that the school implements to a very significant degree the collection of materials in the appropriate recycling bin and their disposal, while the same practice lags far behind in degree and accuracy sorting of recycled materials in the private sphere of family life.

The results show overall satisfactory environmental behavior of students, but there is a need to redesign and implement targeted teaching approaches to update, inform and reinforce those children's daily practices that are necessary for the transition through education from the society of consumption in the society of restraint and prevention.

\section{REFERENCE LIST}

Abdel-Shafy, I.H. \& Mansour, SM. M. (2018). Solid waste issue: Sources, composition, disposal, recycling, and valorization. Egyptian Journal of Petroleum, 27(4), 1275-1290.

Aguilar-Jurado, M.A., Gil-Madrona, P., Ortega-Dato, J.F. \& Zamorano-García, D. (2019). Effects of an Educational Glass Recycling Program against Environmental Pollution in Spain. International Journal of Environmental Research and Public Health, 16, 5108.

Aither. (2018). A Guide to Managing Water for the Environment (a framing paper for the High Level Panel on Water). Australian Water Partnership, Canberra.

Akitsu, Y., Ishihara, K. N., Okumura, H. \& Yamasueb, E. (2017). Investigating Energy Literacy and its Structural Model for Lower Secondary Students in Japan. International Journal of Environmental \& Science Education, 12(5), 1067-1095.

Brusarosco, A. (2015). Individual daily choices for mitigation. Accessed 1-12-2020 from: CLICHA: 8.2 Individual daily choices for mitigation (sameworld.eu)

Cleveland, C., \& Morris, C. (2009). Dictionary of Energy: Expanded Edition. Elsevier Science.

Correljé, A. \& van der Linde, C. (2006). Energy supply security and geopolitics: A European perspective. Energy Policy, 34(5), 532-543.

Cotton, R. E. D., Miller, W., Winter, J., Bailey, I. \& Sterling, S. (2015). "Developing students' energy literacy in higher education", International Journal of Sustainability in Higher Education, 16(4), 456-473.

D’Agosto, de A. M. (2019). Chapter 7 - Noise pollution, vibration, visual intrusion, and emission of solid and liquid waste. Transportation, Energy Use and Environmental Impacts Elsevier, p. 259-280. http://www.sciencedirect.com/science/article/pii/B9780128134542000076

Densley Tingley, D. \& Davison, B. (2011). Design for deconstruction and material reuse. Proceedings of the Institution of Civil Engineers - Energy, 164(4), 195-204. ISSN 1751-4223, E-ISSN 1751-4231.

DeWaters, J. \& Powers, S. (2008). Energy literacy among middle and high school youth. 38th Annual Frontiers in Education Conference, Saratoga Springs, NY, USA, 2008, pp. T2F-6-T2F-11, doi: 10.1109/FIE.2008.4720280.

Dobravec, V., Matak. N., Sakulin, C. \& Krajačić, G. (2021). Multilevel governance energy planning and policy: a view on local energy initiatives. Energy, Sustainability and Society, 11(2), https://doi.org/10.1186/s13705-020-00277-y

Edenhofer, O., Pichs-Madruga, R., Sokona, Y., Seyboth, K., Matschoss, P., Kadner, S. \& von Stechow, C. (2011). Renewable Energy Sources and Climate Change Mitigation. Cambridge: Cambridge University Press. http://dx.doi.org/10.1017/CBO9781139151153

Energy Information Administration, (EIA - U.S.). (2016). International Energy Outlook, 2016.

Environmental Protection Agency, (EPA). (2016). Wastes- WasteWise Program. Environmental Factoids. Available online: https://archive.epa.gov/epawaste/conserve/smm/wastewise/web/html/factoid.html [Accessed: December 3, 2020].

European Commission, EC. (2016). Study on the Energy Saving Potential of Increasing Resource Efficiency - Final Report. Luxembourg: Publications Office of the European Union. ISBN 978-92-79-62226-7. 
European Environment Agency (E.E.A, 2019). Energy. https://www.eea.europa.eu/el/themes/energy/intro [Accessed: December 8, 2019].

Ferronato, N. \& Torretta, V. (2019). Waste Mismanagement in Developing Countries: A Review of Global Issues International Journal of Environmental Research and Public Health, 16(6), 1060.

Grosse, F. \& Mainguy, G. (2010). Is recycling "part of the solution"? The role of recycling in an expanding society and a world of finite resources. S.A.P.I.EN.S [Online], 3(1). https://journals.openedition.org/sapiens/906

Guerrero, L.A, Maas G. \& Hogland W.(2013). Solid waste management for cities in developing contries, Waste Management, 33(1), 220-132.

Hanania, J., Stenhouse, K. \& Donev, J. (2018). Energy Education - Embodied energy [Online]. Available: https://energyeducation.ca/encyclopedia/Embodied energy. [Accessed: February 14, 2021].

Hengel, D. (2019). The Geopolitics of Energy. Available online: http://www.afsa.org/sites/default/files/syllabus-geopolitics-of-energy-fall-2019.pdf [Accessed: December 3, 2020].

Henke, I., Cartenì, A., Molitierno, C. \& Errico, A. (2020). Decision-Making in the Transport Sector: A Sustainable Evaluation Method for Road Infrastructure. Sustainability, 12(3), 764, doi:10.3390/su12030764

Kavvada, O., Horvath, A., Stokes-Draut, J., Hendrickson, T. P., Eisenstein, W. A. \& Nelson, K. L. (2016). Assessing Location and Scale of Urban Nonpotable Water Reuse Systems for LifeCycle Energy Consumption and Greenhouse Gas Emissions. Environmental Science \& Technology, 50(24), 1318413194.

Khalil, M. (2018). How Small Choices You Make on a Daily Basis Impact Global Environment Available online: https://infonile.org/en/2018/07/environmental-consciousness-a-guide/

Lefkeli, S., Manolas, E., Ioannou, K. \& Tsantopoulos, G. (2018). Socio-Cultural Impact of Energy Saving: Studying the Behaviour of Elementary School Students in Greece. Sustainability, 10(3), 737. doi:10.3390/su10030737

Manisalidis, I., Stavropoulou, E., Stavropoulos, A. \& Bezirtzoglou, E. (2020). Environmental and Health Impacts of Air Pollution: A Review. Frontiers in Public Health, 8(14). doi:10.3389/fpubh.2020.00014

Maqbool, R., Deng, X. \& Rashid, Y. (2020). Stakeholders' satisfaction as a key determinant of critical success factors in renewable energy projects. Energy, Sustainability and Society, 10(28). https://doi.org/10.1186/s13705-020-00259-0

Martins, A., Madaleno, M. \& Dias, F.M. (2020). Energy literacy: What is out there to know?. Energy Reports, 6 (1), 454-459, ISSN 2352-4847.

Minghua, Z., Xiumin, F., Rovetta, A., Qichang, H., Vicentini, F., Bingkai, L., Giusti, A. \& Yi, L. (2009). Municipal solid waste management in Pudong New Area, China. Waste Management, 29(3), 12271233.

Ntona, E., Arabatzis, G. \& Kyriakopoulos, G. L. (2015). Energy saving: Views and attitudes of students in secondary education. Renewable and Sustainable Energy Reviews, 46, 1-15.

Ole Gunnar, A. (2018). Concepts of Geopolitics and Energy Security. IAEE Energy Forum Second Quarter 2018. IAEE Energy Forum (pp.25-28.) Edition 1, Chapter 3, Publisher: International Association for Energy Economics (IAEE).

Owusu, A. P. \& Asumadu-Sarkodie, S. (2016). A review of renewable energy sources, sustainability issues and climate change mitigation. Cogent Engineering, 3: 1167990.

Papavasileiou, V. (2015). Sustainable Development and Education: A multidimensional relationship. Athens: Diadrasi. (in Greek)

Papavasileiou, V., Nikolaou, E., Xanthacou, Y. Papadomarkakis, I., Matzanos, D. \& Kaila, M. (2017). Student preschool teachers' views about the pedagogical context of sustainable kindergarten. Proceedings of INTCESS 2017 4th International Conference on Education and Social Sciences. Istanbul, Turkey, 6-8 February, 2017.

Papavasileiou, V., Nikolaou, E., Xanthacou, Y., Xanthis, A., Matzanos, D. \& Kaila, M. (2018). Organization - 
pedagogical use of the spaces in the sustainable kindergarten: views of preschool education graduate students. IJAEDU- International E-Journal of Advances in Education, Vol. IV, Issue 12, 245-250, http://ijaedu.ocerintjournals.org /download/article-file/615354

Poore, J. \& Nemecek, T. (2018). Reducing food's environmental impacts through producers and consumers. Science, 360 (6392), 987-992.

Ritchie, H. (2020). Environmental impacts of food production Published online at OurWorldlnData.org. Retrieved 2.12.2020 from: https://ourworldindata.org/environmental-impacts-of-food [Online Resource]

Ritchie, H. (2019). Clean Water". Published online at OurWorldInData.org. Retrieved 2.12.2020 from: https://ourworldindata.org/water-access [Online Resource]

Scarlat, N., Fahl, F. \& Dallemand, J-F. (2019). Status and Opportunities for Energy Recovery from Municipal Solid Waste in Europe. Waste and Biomass Valorization, 10, 2425-2444.

Stulz, R., Tanner, S. \& René Sigg, R. (2011). Chapter 16 - Swiss 2000-Watt Society: A Sustainable Energy Vision for the Future. Energy, Sustainability and the Environment, p. 477-496, ISBN 9780123851369.

Supasa, T., Hsiau S-S., Lin S-M., Wongsapai, W. \& Wu, J-C. (2017). Household Energy Consumption Behaviour for Different Demographic Regions in Thailand from 2000 to 2010. Sustainability, 9, 2328. doi:10.3390/su9122328.

Tukker, A. \& Jansen, B. Environment impacts of products-A detailed review of studies. Journal of Industrial Ecology, 10 (3), 159-182.

Tuladhar, R. \& Yin, S. (2019). Sustainability of using recycled plastic fiber in concrete. In (eds) F. PachecoTorgal, J. Khatib, F. Colangelo. \& R. Tuladhar, Use of Recycled Plastics in Eco-efficient Concrete, 441-460, Woodhead Publishing.

U.S. Environmental Protection Agency, EPA US (xx). Water Reuse and Recycling: Community and Environmental Benefits. Accessed 1.12.2020, https://www3.epa.gov/region9/water/recycling/\#benefits

U.S. Environmental Protection Agency, (EPA). (xx). Wastes - WasteWise Program. Environmental Factoids. Accessed 1.12.2020 https://archive.epa.gov/epawaste/conserve/smm/wastewise/web/html/factoid.html

United Nations. (XX). The Ecology of Recycling. Accessed 1-12-2020 from: https://www.un.org/en/chronicle/article/ecology-recycling

Vezzoli, C., Ceschin, F., Osanjo, L., M'Rithaa, K. M., Moalosi, R., Nakazibwe, V. \& Diehl, J. C. (2018). Designing Sustainable Energy for All: Energy and Sustainable Development, p. 3-22. Springer, Cham.

Warunasinghe, W. A. A. I. \& Yapa, P. I. (2016). A survey on household solid waste management (SWM) with special reference to a peri-urban area (Kottawa) in Colombo. Procedia Food Science, 6, $257-260$.

Weber, L.C. \& Matthews, H.S. (2008). Food-Miles and the Relative Climate Impacts of Food Choices in the United States. Environmental Science \& Technology, 42(10).

World Petroleum Council. (2020). Alternative Transport Fuels - Courtesy of AIP. Accessed 1-12-2020 http://www.world-petroleum.org/technology/202-alternative-transport-fuels-courtesy-of-aip

Young, J. T. (2015). Questionnaires and Surveys. In (ed) Z. Hua, Research Methods in Intercultural Communication: A Practical Guide, Wiley-Blackwell, 163-180. 